\title{
AS TRADUÇÕES E AS ADAPTAÇÕES PARA O INGLÊS DE $A L I$ BABÁ E OS QUARENTA LADRÕES NOS SÉCULOS XVIII E XIX
}

\author{
Daniel Padilha Pacheco da Costa ${ }^{1^{*}}$ \\ ${ }^{1}$ Universidade Federal de Uberlândia, Uberlândia, Minas Gerais, Brasil
}

\section{Resumo}

Neste artigo, procura-se reconstituir a tradição editorial inaugurada no início do século XVIII pela primeira tradução para o inglês da fábula de Ali Babá e os quarenta ladrões. Durante os dois séculos seguintes, foram realizadas a partir dessa versão centenas de reedições e de adaptações para o inglês que, direta ou indiretamente, foram mediadas pela versão francesa de Antoine Galland, que foi o responsável por introduzir, pela primeira vez, aquela fábula na coletânea árabe chamada de As mil e uma noites. Pretende-se analisar os diferentes procedimentos literários, tradutórios e editorais utilizados pelos agentes envolvidos na sua popularização em países anglófonos desde sua tradução indireta para o inglês, até sua adaptação nos diferentes formatos de chapbooks publicados durante todo o século XIX.

Palavras-chave: Estudos da Tradução; Estudos da Adaptação; Chapbooks; As mil e uma noites; Ali Babá e os quarenta ladrões.

\section{THE TRANSLATIONS AND ADAPTATIONS INTO ENGLISH OF ALI BABA AND THE FORTY THIEVES IN THE EIGHTEENTH AND NINETEENTH CENTURIES}

\begin{abstract}
This paper aims to reconstruct the editorial tradition which began in the early eighteenth century with the first English version of Ali Baba, and the forty thieves. During the next two centuries, this version gave origin to a great number of editions and adaptations into English, which were directly or indirectly mediated by Antoine Galland's French version, who was responsible in the first place for introducing this tale into the Arabic compilation known as The Thousand and One Nights. It is my intention to analyze the different literary, translation and editorial procedures used by the agents involved in the tale's popularization, fromits indirect translation into English to its adaptation into the different formats of chapbooks published throughout the nineteenth century.

Keywords: Translation Studies; Adaptation Studies; Chapbooks; The Thousand and One Nights; Ali Baba, and the Forty Thieves.
\end{abstract}

\footnotetext{
* Professor do Programa de Pós-Graduação em Estudos Literários e do Curso de Graduação em Tradução do Instituto de Letras e Linguística da Universidade Federal de Uberlândia. Doutor pelo Departamento de Letras Modernas da Universidade de São Paulo (Programa de Estudos Linguísticos, Literários e Tradutológicos em Francês). Graduado em Filosofia pela Universidade de São Paulo e em Literatura Francesa pela Université Sorbonne Nouvelle (Paris III). Atualmente, desenvolve pesquisas em Literatura Comparada e Tradução, com ênfase em Literatura Francesa. Seu e-mail é: dppcost@ufu.br; ORCID: 0000-0003-4947-1295.
} 


\section{As mil e uma noites, em tradução}

A coletânea de fábulas ${ }^{1}$ árabes Alf Layla wa-Layla (O livro das mil e uma noites) foi introduzida no Ocidente por meio da versão francesa do orientalista Antoine Galland (1646-1715). O tradutor francês pode ser considerado como um dos principais integrantes do seleto grupo de orientalistas que os países da Europa formaram para erigir a pedra fundamental da chamada Biblioteca oriental (Galland, 1777). O orientalismo ${ }^{2}$ de Galland fica evidente em seu prefácio à Bibliothèque orientale, ou Dictionnaire universel contenant tout ce qui fait connaitre les peuples de l'Orient (1697), de Barthélemy d'Herbelot, definida por Said $(1977,64)$ como "a suma do orientalismo do século XVII".

Segundo a concepção cristã da "natureza feminina" como volúvel, a metáfora das belles infidèles (belas infiéis) foi utilizada na França dos séculos XVII e XVIII para definir uma prática tradutória na qual a fidelidade ao texto deveria ser sacrificada em prol de sua adaptação às convenções letradas da instituição literária. A tradução não era, assim, considerada como uma prática autônoma, como passaram a fazê-lo os filólogos alemães do início do século XIX, mas como uma das modalidades da imitação, junto à adaptação, à emulação e à paródia, por exemplo. Em seu ensaio Los traductores de las 1001 noches, publicado em Historia de la Eternidad (1936), o escritor argentino Jorge Luis Borges utiliza essa metáfora para descrever a tradução de Galland.

Nesse ensaio, Borges (1984, 398, tradução nossa), que foi um colecionador de paradoxos, salienta este fato curioso: "Palavra por palavra, a versão de Galland é a mais mal escrita, a mais impostora e a mais fraca de todas, mas foi a mais bem lida". Tendo acrescentado fábulas fundamentais (que o próprio "original" desconhece), criado um cânone literário (talvez o mais lido), tendo sido a mais apreciada (e recebido os mais famosos e felizes elogios), e tendo sido passada para as mais diversas línguas (inclusive o hindu e o árabe), a versão de Galland pode ser considerada como a principal representante da tradição tradutória das belas infiéis. Por esse motivo, como afirma o escritor argentino, suas "agressões" seriam "magias", e suas "licenças" "jóias" (Borges, 1984, 398).

Desde então, essa coletânea árabe de fábulas não cessou de receber novas traduções nas mais diversas línguas ocidentais, e os prolongamentos da tradição editorial iniciada pela versão de Galland se estendem até hoje. Isso se deve à reunião em torno desse livro de um conjunto (único, talvez) de circunstâncias: a exponencial quantidade que recebeu de edições, traduções e adaptações (em todos os suportes semióticos), a introdução que promoveu de novas fábulas particularmente apreciadas pelo público no interior de uma tradição oral e escrita multissecular e a posição que ocupou como inesgotável fonte de inspiração para novas histórias em diferentes tradições literárias. ${ }^{3}$

Neste artigo, são reconstituídos os dois primeiros séculos da tradição editorial inaugurada pelas traduções e adaptações para o inglês da fábula de Ali Babá e os quarenta ladrões, que foi incluída pelo orientalista francês Antoine Galland em sua tradução Les mille et une nuits. Pretende-se descrever os procedimentos 
literários, tradutórios e editorais utilizados pelos diferentes agentes (escribas, tradutores, adaptadores, revisores, editores, impressores e críticos) envolvidos na popularização dessa fábula em países anglófonos, como o Reino Unido e os Estados Unidos, desde sua tradução indireta para o inglês, mediada pela versão de Galland, no início do século XVIII, até sua adaptação nos diferentes formatos de chapbooks publicados durante todo o século XIX.

\section{As traduções diretas de As mil e uma noites}

Em seu ensaio publicado sobre os principais tradutores europeus de As mil e uma noites, o escritor argentino Jorge Luis Borges foca sua atenção naqueles que as traduziram diretamente para o francês, alemão e inglês. Como foi dito, a primeira tradução de As mil e uma noites em uma língua europeia foi realizada diretamente a partir do árabe no início do século XVIII pelo orientalista francês Antoine Galland. Essa tradução foi publicada em 12 volumes em Paris, com o título Les mille et une nuits (1704-1717) (os quatro primeiros volumes foram publicados em 1704; V e VI, em 1705; VII, em 1706; VIII, em 1709; IX e X, em 1712; e, postumamente, XI e XII, em 1717).

Durante o século XVIII, foram publicadas 20 reedições e, somente entre 1811 e 1820, 54 reedições de Les mille et une nuits (Guedes, 2002). A versão de Galland foi a responsável pela criação de um novo gênero literário em língua francesa. Pertencem a esse novo gênero literário diversas obras que imitam a estrutura narrativa de Les mille et une nuits, como Mille et un jours (1710-1712), de Pétis de la Croix, Les mille et un quart-d'heure: contes Tartares (1715), de Gueullette, e a coletânea de fábulas Le Bélier, l'Histoire de Fleur d'Épine, Les Quatre Facardins d'Hamilton (1730), de Antoine Hamilton.

Em seu ensaio, Borges (1984) também analisa a tradução francesa de Joseph Charles Mardrus (1868-1949), publicada em Paris em 16 volumes e intitulada Le livre des mille nuits et une nuit (1899-1903), bem como a tradução alemã de Enno Littmann (1875-1958), publicada em Leipzig em seis volumes e intitulada Die Erzählungen aus den Tausendundein Nächten (1923-1928). No entanto, o interesse do escritor argentino se volta, principalmente, para as diferentes traduções para o inglês que, realizadas durante o século XIX por importantes orientalistas, arabistas e tradutores - como Edward William Lane (1801-1876), John Payne (1842-1916) e Richard Francis Burton (1821-1890) -, são consideradas como "traduções melhores" do que a francesa (Borges, 1984, 397).

Diretamente realizadas a partir de manuscritos e edições árabes, as traduções de Lane, Payne e Burton rompem com a tradição anterior de traduzir a versão de Galland. Somente em meados do século XIX, foi publicada a primeira tradução direta para o inglês da célebre coletânea árabe. Ela foi realizada por Edward William Lane e publicada em três volumes com o título The Thousand and One Nights, Commonly Called, in England, The Arabian Nights' Entertainments: A New Translation from the Arabic, with Copious Notes (1838-41). ${ }^{4}$ Essa tradução não mantém a tradicional divisão da coletânea árabe em noites, mas a reorganiza 
em trinta capítulos. Para a tradução dos nomes próprios dos personagens, Lane adota um sistema de transcrição em inglês a partir do árabe, em vez de manter os nomes consagrados pela tradução anterior. O nome do marujo Simbad, por exemplo, recebe a tradução de "Es-Sindibád" (STORIES, 1909, 231).

Henry Whitelock Torrens (1806-1852) iniciou uma tradução direta a partir da segunda edição de Calcutá, baseada em um manuscrito do ramo egípcio tardio. No entanto, decidiu interromper sua tradução, quando descobriu que Lane também estava trabalhando em uma tradução direta do árabe daquela coletânea de fábulas (Marzolph, 2004). Essa tradução incompleta para o inglês foi publicada, em Londres, em um único volume, intitulado The Book of the Thousand Nights and one Night (1838).

No final do século XIX, foram realizadas mais duas traduções diretas de As mil e uma noites para o inglês por John Payne e Richard Francis Burton. Intitulada The Book of the Thousand Nights and One Night: now first completely done into English prose and verse, from the original Arabic (1882-1884), a tradução de Payne foi publicada em nove volumes em Londres. Ela recebeu um suplemento, publicado em três volumes com o título Tales from the arabic (1884). Payne apresenta explicitamente sua tradução como uma correção da tradução erudita de Lane, com vistas a resgatar o caráter literário da antiga versão de Galland, em detrimento dos objetivos históricos e filológicos priorizados por Lane (Arata, 2014). Naquela época, ela foi a mais completa tradução em inglês, possuindo "quatro vezes" a extensão da tradução de Galland (THE BOOK, 1884, 7).

A tradução de Burton se intitula The Book of the Thousand Nights and a Night (1885) e foi publicada em dez volumes em Londres. Essa edição recebeu um suplemento, publicado em cinco volumes em Londres e intitulado Supplemental Nights to the book Thousand Nights and a Night, with notes anthropological and explanatory (1886-1888). Ela também se apresenta como uma correção da tradução de Lane, reintroduzindo e, até mesmo, exacerbando os termos obscenos explicitamente censurados por ele. O biógrafo de Burton e de Payne, Thomas Wright, acusa o primeiro de ter plagiado o segundo, mas essa opinião não foi aceita pela crítica especializada (Marzolph, 2004). A tradução de Burton se tornou a versão de referência da coletânea árabe em inglês.

A primeira tradução direta do árabe para o português só foi publicada no início do século XXI, com o título de O livro das mil e uma noites, em quatro volumes (2005-2012). Seu tradutor é o arabista brasileiro Mamede Mustafa Jarouche (1963-). Seus dois primeiros volumes incluem as fábulas do ramo sírio, e os dois últimos as do ramo egípcio. Ausentes de qualquer versão árabe, as fábulas de Aladim e de Ali Babá são incluídas em anexo ao quarto volume (LIVRO, 2012). Como Lane, Jarouche também adota um sistema de transcrição em português dos nomes próprios dos personagens a partir do árabe. Além dessa edição completa, $\mathrm{o}$ tradutor português Hugo Maia verteu diretamente uma centena de noites em sua edição do primeiro volume de As mil e uma noites (2017). A tradução realizada pelo imperador D. Pedro II também foi feita diretamente do árabe no final do século XIX (1887-1891), mas permaneceu inédita (Souza, 2015). 


\section{As traduções indiretas de As mil e uma noites}

Desde o início do século XVIII, foram realizadas traduções indiretas para diferentes línguas europeias com base na versão francesa. A tradução inglesa Arabian Nights' Entertainments: Consisting of One Thousand and One Stories (1706-1721) foi publicada em 12 volumes em Londres, imediatamente depois da versão francesa. Essa tradução anônima é conhecida como "Grub Street edition" (edição de Grub Street) e foi reeditada em cinco volumes em Londres (1772), em quatro volumes em Edimburgo, e mais três vezes em 1778, 1792 e 1798 (SUPPLEMENTAL, 1886, 468). Recentemente, foi reeditada por Robert L. Mack (2006). O subtítulo dessa tradução é uma longa descrição:

Arabian Nights Entertainments consisting of one thousand stories: told by the sultaness of the Indies, to divert the sultan from the execution of a bloody vow he had made, to marry a lady every day, and have her head cut off next morning, to avenge himself for the disloyalty of the first sultaness, also containing a better account of the Customs, Manners and Religion of the Eastern Nations, viz., Tartars, Persians and Indians, than is to be met with in any Author hitherto published. (ARABIAN, 1792, 5). ${ }^{5}$

A tradução em alemão por Talander, Die tausend und eine Nacht (17101719), publicada em Leipzig em 12 volumes também foi mediada pela versão de Galland. Da mesma forma que a inglesa, a tradução alemã foi publicada imediatamente depois da versão francesa. Segundo o recenseamento de Marzolph (2004), As mil e uma noites também foram traduzidas indiretamente para o italiano (1722), o holandês (1732), o dinamarquês (1745), o russo (1763-1771), o polonês (1768), o espanhol (s./d.; 1846) e o tcheco (1859-1862). A grande maioria dessas traduções indiretas é anônima, com exceção da tcheca e da russa, realizadas, respectivamente, por Josef Pecírka e por A. Filatoff.

No início do século XIX, foi publicada, em Lisboa, a tradução portuguesa de As mil e uma noites: contos arábicos (1801-1803). Realizada indiretamente, essa tradução anônima foi responsável pela apresentação da coletânea árabe ao público dos países lusófonos. ${ }^{6} \mathrm{O}$ tradutor português Martim Velho Sotto Mayor também se baseia na versão francesa para realizar sua edição, publicada pela Estampa em seis volumes (AS MIL, 19-?). Durante todo o século XX, continuaram sendo publicadas, tanto em Portugal quanto no Brasil, traduções realizadas indiretamente com base na versão de Galland. A tradução brasileira realizada por Alberto Diniz indica, na capa, ter sido mediada pela "versão de M. Galland" e inclui uma biografia do tradutor francês e uma carta dedicando sua obra à "Senhora Marquesa d'O" (AS MIL, 1991, 12), além de um prefácio de Malba Tahan.

Nem todas as traduções indiretas para o português foram mediadas pela tradução de Galland. A edição luxuosa, publicada em 1958 e realizada por um "seleto grupo de literatos portugueses", foi mediada pela tradução francesa de Joseph-Charles Mardrus (Jarouche, 2007, 362). A tradução brasileira de As mil e uma noites (1961), realizada por Nair Lacerda (prosa) e Domingos Carvalho da 
Silva (poesia), com a supervisão e o cotejo dos textos árabes por Suleiman Khalil Safady, foi mediada pela tradução inglesa de Burton (Chareti, 2017). A tradução portuguesa de Eduardo Dias, publicada, em seis volumes (1944-1952), em Lisboa, foi mediada, principalmente, pela combinação entre a versão francesa de Galland e a tradução inglesa de Burton, além do eventual cotejo com edições árabes.

Embora indiretas, todas essas traduções para o inglês, alemão, italiano, russo, holandês, dinamarquês, tcheco, polonês, espanhol e português da coletânea de fábulas árabes foram muito populares. A partir do surgimento das teorias da tradução elaboradas pelos filólogos alemães do início do XIX, que opunham a tradução e o "original", as traduções indiretas começaram a se tornar menos aceitas. Isso porque, como "textos mediados", como afirma o teórico Gideon Toury $(1995,130)$, as traduções indiretas de As Mil e uma noites em diversas línguas europeias passaram pelo filtro linguístico e cultural das convenções letradas da instituição literária do século XVIII na França.

Como as traduções, as adaptações da coletânea árabe também desempenharam um papel decisivo na sua popularização, sobretudo juntamente ao público infanto-juvenil. No Brasil, há diversas adaptações de As mil e uma noites destinadas a esse público. A primeira delas foi realizada por Monteiro Lobato e inclui Ali Babá e os 40 ladrões, a Princesa de Deriabar e Codadad e seus irmãos (AS MIL, 2007). A tradução de Galland também foi, recentemente, adaptada em língua portuguesa por Paulo Sérgio de Vasconcellos. Sua adaptação, intitulada Mil e uma noites: contos selecionados (2008), inclui estas quatro fábulas: O pescador e o gênio, Ali Babá e os 40 ladrões, Aventuras de Simbad, o marujo e Aladim e a lâmpada maravilhosa (Vasconcellos, 2008, 14).

Além dessas adaptações realizadas por tradutores brasileiros, também foram traduzidas para o português adaptações em inglês da coletânea árabe, como Aladdin and Other Tales from the Arabian Nights (1998). Essa adaptação britânica, realizada por Rosalind Kerven, inclui, por exemplo, as fábulas de Aladim e a lâmpada maravilhosa e de Ali Babá e os quarenta ladrões (Kerven, 1998). Sua tradução para a língua portuguesa, Aladim e outros contos de As mil e uma noites (1998), foi realizada por Hildegard Feist.

\section{A edição revisada de Jonathan Scott}

No início do séculoXIX, o orientalista Jonathan Scott (1754-1829) ambicionou realizar uma tradução para o inglês do manuscrito árabe que foi comprado pelo professor John White e trazido para a Europa pelo viajante Edward Wortley Montague em 1764. Atualmente, esse manuscrito (Bodl. Or. 550) encontra-se na Biblioteca Bodleiana de Oxford. No entanto, Scott abandonou o projeto, já que, ao comparar o texto da versão francesa com os manuscritos árabes então conservados nessa biblioteca, ele teria chegado à conclusão de que essa versão era "extremamente fiel" (Scott, 1811, 12).

Como a repetição do trabalho de Galland não traria nenhuma novidade, ele decidiu se restringir à realização de uma edição revisada da tradução indireta 
para o inglês. Como justificativa para sua empreitada, Scott $(1811,12)$ afirma ter identificado um elevado número de problemas na "tradução indireta" (double translation) para o inglês. Suas intervenções se concentram, principalmente, em corrigir as passagens que se afastam da versão de Galland. Além disso, a edição revisada de Scott também teria realizado o cotejo da versão francesa com os manuscritos árabes e, com base nesse trabalho, corrigido eventuais passagens em que o próprio Galland teria se afastado do árabe.

Há diversos detalhes e, às vezes, trechos inteiros da versão francesa que, suprimidos pela tradução inglesa, foram reintroduzidos por sua edição revisada. Um exemplo de como esse trabalho de revisão procura seguir de perto a tradução de Galland se encontra na correção introduzida no próprio título da fábula de Ali Babá. O título da edição de Grub Street era: The story of Ali Baba, and the forty thieves (ARABIAN, 1792). Scott introduziu a referência à morte dos quarenta ladrões pelo personagem da escrava Morjana: The History of Ali Baba, and of the Forty Robbers killed by one slave (Scott, 1811, 132). Esse título é uma tradução literal daquele dado por Galland em francês: Histoire d'Ali Baba et de quarante voleurs exterminés par une esclave (LES MILLE, 1704-1717).

A primeira edição de Scott, publicada, em seis volumes (1811), em Londres tornou-se muito popular na época, tendo sido reeditada em quatro volumes por duas vezes no mesmo país em 1882 e 1890. O título completo dado por Scott à sua edição revisada é ilustrativo de suas principais características:

Arabian Nights' Entertainments: consisting of One Thousand and One Stories, carefully revised and occasionally corrected from the Arabic. To which is added, a selection of new tales, now first translated from the Arabic originals. Also, an introduction and notes, illustrative of the religion, manners and customs, of the Mohammedans. (Scott, 1811, 4). ${ }^{8}$

Antes de realizar sua edição, Scott escrevera uma descrição detalhada do conteúdo do manuscrito Bodl. Or. 550. Essa descrição, acompanhada de um sumário de todas as fábulas contidas nesse manuscrito, foi publicada na coleção de ensaios Oriental Collection, editada por Sir William Gore Ouseley (Leslie, 1897). Com base nessa descrição, Scott elencara todas as fábulas presentes naquele manuscrito, mas ausentes da versão francesa. Em sua edição revisada, ele também procedeu a uma tradução direta do árabe dessas fábulas inéditas. Portanto, além de revisar a tradução indireta já existente em inglês, Scott também "completa" sua edição com a tradução dessas fábulas inéditas.

A edição revisada por Scott combina, portanto, duas fontes heteróclitas, incluindo, na edição inglesa de Grub Street, sua tradução de fábulas oriundas do manuscrito árabe. Em sua edição, ele oferece uma longa introdução à tradição manuscrita dos textos árabes então conservados na Biblioteca Bodleiana. Scott inclui, pela primeira vez, copiosas notas explicativas sobre a "religião, os hábitos e os costumes dos maomedanos". As traduções diretas para o inglês de As mil e uma noites realizadas durante o século XIX retomam o recurso às notas explicativas, adotado em sua edição. 


\section{A fábula órfã de Ali Babá e os quarenta ladrões}

No manuscrito árabe traduzido por Galland, datado de 1455 d.C. (o mais antigo do ramo sírio) e conservado na Biblioteca Nacional Francesa em Paris (le manuscrit Arabe 3609-3611), não se encontra a fábula de Ali Babá e os quarentas ladrões. Os diários de Galland contêm anotações sobre essa fábula, indicadas no sumário com o título: "Les finesses de Morgiane ou Les quarante voleurs exterminés par l'adresse d'une esclave" (Chraïbi, 2007, 3). Essas anotações teriam sido realizadas com base no relato oral de um monge maronita de Alepo, na Síria, chamado Hannâ Diyâb. Portanto, a tradução de Galland é a versão escrita mais antiga da fábula de Ali Babá, que teria sido redigida, pela primeira vez, pelo próprio tradutor francês a partir de um testemunho oral.

A única versão árabe da fábula de Ali Babá e os quarenta ladrões se encontra no manuscrito Bodleian Oriental 633, transcrito por um certo Yuhanna ibn Yusuf Warisi. Esse manuscrito foi adquirido pela Biblioteca Bodleiana em 1860, mas permaneceu inteiramente desconhecido até o início do século XX. Descoberto em 1908 pelo orientalista alemão Carl Hermann Ethé, esse manuscrito foi publicado pelo arabista escocês Duncan Macdonald (1910) em uma revista europeia. A verdadeira identidade do autor desse manuscrito é a do arabista francês Jean Varsy, como demonstrou Macdonald (1913). ${ }^{9}$

Desde a descoberta desse misterioso manuscrito árabe na própria Biblioteca Bodleiana de Oxford, sua autentidade tem sido objeto de desconfiança por parte de arabistas (LIVRO, 2012). Já tinham sido forjados, para serem vendidos como autênticos, outros manuscritos árabes de As mil e uma noites - como os dois manuscritos árabes de Aladim e a lâmpada mágica transcritos, respectivamente, por Dom Denis Chavis e por Mikhail Sabbagh. ${ }^{10}$ Muito pouco se sabe sobre o lugar, a data e a circunstância em que o manuscrito Bodleian Oriental 633 teria sido transcrito, mas não há dúvidas de que ele é moderno e, portanto, posterior à versão francesa (Macdonald, 1910).

No final do século XX, o crítico iraquiano Muhsin Mahdi defendeu a posição mais influente a respeito desse manuscrito, no ensaio intitulado Retranslation: An arabic version of 'Ali Baba' e publicado no terceiro volume de sua edição crítica do ramo sírio de As mil e uma noites. ${ }^{11}$ Mahdi (1994) não apenas recusa categoricamente a autenticidade desse manuscrito, como também procura demonstrar que ele não está vinculado à suposta fonte manuscrita traduzida por Galland nem a uma fonte independente dessa última, mas é uma retrotradução em árabe da versão francesa. Além disso, Varsy teria procurado maquiar sua retrotradução por meio de grande número de amplificações, para apresentá-la como a única transcrição autêntica da fábula de Ali Babá.

Com base na autoridade de Mahdi, a maioria dos críticos (Marzolph, 2004; Mahdi, 2008; Arata, 2014) considera atualmente que o manuscrito Bodleian Oriental 633 seria uma retrotradução da versão francesa. Arabistas como Mamede Mustafa Jarouche (LIVRO, 2012) e Katia Zakharia (2017), no entanto, levantaram dúvidas sobre essa hipótese hegemônica. Embora concordem que o 
manuscrito árabe da fábula de Ali Babá, de fato, não é a fonte da versão francesa, eles afirmam que esse manuscrito poderia ser autêntico, pertencendo a uma tradição manuscrita independente de Galland. Por isso, o arabista brasileiro opta por realizar sua tradução dessa fábula a partir do manuscrito de Varsy, oferecendo a única tradução dessa fábula para o português a partir do árabe.

Para sua tradução, Edward William Lane se baseia em vários manuscritos e edições árabes, utilizando os critérios filológicos próprios do início do período vitoriano para estabelecer o suposto texto autêntico de As mil e uma noites. Lane excluiu de sua tradução a fábula de Ali Babá e os quarenta ladrões, considerada como "inautêntica" e como simples fruto da imaginação do tradutor francês (Arata, 2014, 1013). Da mesma forma, a tradução de Torrens e a de Payne também a excluíram. Ao contrário do que fizeram esses três tradutores, Burton decidiu introduzir essa fábula em sua própria edição.

A tradução de Burton inclui o conjunto das fábulas órfãs, chamadas pelo orientalista inglês de "Gallandian histoires" (THE BOOK, 1885, 7). As nove fábulas órfãs, inclusive Ali Babá e os quarenta ladrões, foram introduzidas no terceiro volume do suplemento à sua tradução. Richard Burton baseou sua tradução da fábula de Ali Babá na própria versão francesa, mesmo que essa versão não se baseie em nenhum manuscrito conhecido. No prefácio à sua tradução das fábulas órfãs, Burton reconhece temer a ruptura estilística introduzida pela sua "retradução" dessas fábulas mediadas pela versão francesa (THE BOOK, 1885, 590). Para remediar tal ruptura, afirma ter chegado a cogitar traduzi-las inicialmente para o árabe, antes de vertê-las para o inglês. Por fim, decide utilizar a tradução indiana de Totárám Sháyan, publicada em dois volumes (1862-1869).

Assim como Burton, o editor e revisor da tradução de Lane - seu sobrinho Stanley Edward Lane-Poole - reintroduziu a fábula de Ali Babá em sua reedição da tradução do tio, intitulada Stories from The Thousand and One Nights (1909). Ela é disposta em um apêndice especificamente dedicado às fábulas 'Ali Baba e Alaed-Din, traduzidas não por Lane, mas pelo próprio editor. Na nota introdutória de sua edição, ele salienta que a fábula de Ali Baba and the Forty Thieves não se encontra em nenhuma versão oriental de As mil e uma noites, mas foi introduzida nessa coletânea por Galland (STORIES, 1909).

Com base nas informações atualmente disponíveis, não é possível saber qual teria sido a fonte da versão francesa da fábula Ali Babá, e nem sequer se essa fonte era manuscrita ou oral. Por isso, a fábula Ali Babá é considerada como uma "orphan story" (Gerhardt, 1963, 12). Sua presença no interior da versão francesa da coletânea árabe demonstra que Antoine Galland poderia ser não apenas o tradutor de As mil e uma noites, mas também o autor de algumas de suas fábulas mais populares, como a de Ali Babá.

Se o manuscrito árabe de Varsy é, de fato, uma retrotradução, então as traduções do manuscrito árabe de Ali Babá, como a de Jarouche, devem ser consideradas como indiretas, ainda que as traduções das demais fábulas sejam realizadas diretamente a partir de manuscritos árabes autênticos; e, inversamente, as traduções dessa fábula para diferentes línguas europeias que foram mediadas 
pela versão francesa devem ser consideradas como traduções diretas, ainda que a tradução do restante das fábulas seja indireta.

\section{A genealogia dos chapbooks de Ali Babá}

Desde o início do século XIX, foram publicados centenas de chapbooks ${ }^{12}$ (livros populares) contendo fábulas oriundas de As mil e uma noites. Essas edições se basearam em suas respectivas traduções para diferentes línguas. As principais fábulas publicadas em formato de chapbook são, precisamente, as que se tornaram mais populares desde a versão de Galland, como Aladim e a lâmpada mágica e Ali Babá e os quarenta ladrões. Esses chapbooks confirmam um dos aspectos característicos dessa "fórmula editorial" que, como afirma Chartier $(1990,166)$, utiliza, na maior parte das vezes, textos que remontam a uma tradição erudita prévia, não textos escritos especificamente para tal finalidade.

Durante o século XIX, foi publicado em inglês um grande número de chapbooks baseados na fábula de Ali Babá. Para compreendê-los, procurou-se traçar sua genealogia, classificar seus conteúdos e seguir suas transformações (Chartier, 1990). Embora haja exceções, a maioria dos chapbooks sobre a fábula de Ali Babá, realizados ao longo de todo o século XIX em diferentes países anglófonos, como o Reino Unido e os Estados Unidos, baseou-se na tradição editorial inaugurada pela tradução indireta para o inglês.

No entanto, essa tradição editorial não é homogênea, mas recebeu diversas reedições durante o século XVIII, sem contar a edição revisada de Scott. Para descobrir qual tradução foi utilizada nos chapbooks de Ali Babá, é preciso realizar uma comparação entre as passagens contidas na tradução de Galland que foram suprimidas pela tradução de Grub Street e reintroduzidas pela edição de Scott. No final da fábula de Ali Babá, a descrição do enterro dos 39 ladrões, realizado por Ali Babá e por seu escravo Abdalla (depois que eles foram assassinados pela astuta escrava Morjana), suprimida pela edição de Grub Street, foi reintroduzida por Scott em sua edição revisada:

'All that we have to do is to bury the hodies of these pests of mankind immediately, and with all the secrecy imaginable, that nobody may suspect what is become of them. But that labour Abdoollah and I will undertake'. Ali Baba's garden was very long, and shaded at the farther end by a great number of large threes. Under these he and the slave dug a trench, long and wide enough to hold all the robbers, and as the earth was light, they were not long in doing it. (Scott, 1811, 170). ${ }^{13}$

Como os chapbooks a seguir mencionam a descrição do enterro dos 39 ladrões por Ali Babá e seu escravo Abdalla, é possível afirmar que eles se baseiam diretamente na edição revisada por Scott. Embora esses chapbooks remontem, em última instância, à edição de Scott, nem todos foram diretamente realizados a partir dessa tradução. Em alguns casos, é possível encontrar um chapbook (ele 
mesmo baseado diretamente na edição de Scott) interposto entre outro chapboook e a edição de Scott, como será visto a seguir.

\section{Os chapbooks condensados de Ali Babá}

É comum a publicação de chapbooks contendo várias fábulas. Entre os chapbooks sobre As mil e uma noites, aquele intitulado Sindbad, the sailor and Ali $B a b a$, and the forty thieves (1895), por exemplo, publicado em Nova Iorque, reúne duas fábulas. Os chapbooks em inglês sobre a fábula de Ali Babá incluem formatos integrais. O chapbook intitulado The story of the forty robbers destroyed by a slave (1895), por exemplo, contém 80 páginas e constitui uma reprodução integral da edição revisada de Scott. Com exceção de algumas reproduções integrais, a maioria dos chapbooks sobre a fábula de Ali Babá constituem adaptações, pois suas versões foram sempre condensadas.

A extensão dos chapbooks sobre a fábula de Ali Babá é uma característica formal que varia, como acontece em outros chapbooks. Essa fábula foi publicada em diferentes formatos condensados. As adaptações das fontes letradas pelos chapbooks de Ali Babá utilizam dois procedimentos distintos de condensação, seja combinadamente, seja isoladamente: a abreviação e/ou a simplificação. As condensações utilizam sistematicamente a abreviação de episódios considerados como supérfluos, a simplificação de fórmulas envelhecidas ou difíceis, a contração de frases e a supressão de adjetivos e advérbios.

Há três formatos abreviados nos chapbooks de Ali Babá em inglês: os impressos com 8, 16 e 24 páginas. As abreviações mais intensas entre os chapbooks de Ali Babá podem atingir apenas $10 \%$ da extensão inicial. O chapbook intitulado Ali Baba, or the forty thieves destroyed by Morgiana, a slave (1816), contém 24 páginas. Ele recebeu diferentes reedições ao longo do século XIX. Duas reedições foram realizadas com o mesmo título em 1813 e 1816. Outras quatro reedições, realizadas em 1825, 1827, 1840 e 1850, receberam o acréscimo do subtítulo "um conto interessante": Ali Baba: or the story of the Forty Thieves, an interesting tale (ALI, 1816). Essa versão é responsável pela introdução de algumas variantes na fábula de Ali Babá, como testemunha sua versão do enterro dos ladrões, segundo a qual Ali Babá, auxiliado pela escrava Morjana (e não por Abdalla), teria enterrado 37 (e não 39) ladrões na noite seguinte ao assassinato deles: "And without letting anybody else into the secret, he and Morgiana, the next night, buried the thirty-seven thieves in a deep trench at the bottom of the garden" (ALI, 1850, 16). ${ }^{14}$

O chapbook intitulado History of the Forty Robbers (1867), publicado em Edimburgo, é o mais curto de todos, somando oito páginas. Ele contém a variante mais importante do chapbook anterior, ao afirmar que, na noite seguinte, os ladrões foram enterrados com o auxílio de Morjana. No entanto, ele corrige o número de ladrões, que poderia ter sido deduzido, já que, dos quarenta ladrões, apenas o capitão sobrevive ao assassinato com óleo quente pela escrava Morjana: "Without letting anyone into the secret, Ali Baba and Morgiana the next night buried the 
thirty-nine thieves at the bottom of the garden" (HISTORY, 1867, 7). ${ }^{15}$ Como essas variações foram introduzidas pela versão de 1816 do chapbook, é possível afirmar que essa versão mediou a versão de 1867. Ela constitui uma versão mais curta da anterior, que recebeu um elevado número de reedições, podendo ser descrita como uma adaptação indireta (a adaptação de uma adaptação).

A versão de 1816 da fábula de Ali Babá, dotada de 24 páginas, também serviu de base para chapbooks posteriores. Isso pode ser observado na versão incluída na coletânea escocesa de contos de fadas destinada ao público infanto-juvenil, intitulada Favourite Fairy Tales (1869). Essa edição, publicada em Edimburgo, inclui, em suas duzentas páginas, mais dez contos, como Robin Hood e Cinderella and the little glass-slipper. Sua versão da fábula de Ali Babá possui as mesmas 24 páginas daquele chapbook reeditado várias vezes desde a primeira edição de 1816 e, apesar das simplificações linguísticas e estilísticas, oferece a mesma interpretação para o enterro dos ladrões, deixando implícito que Morjana teria auxiliado Ali Babá a enterrar os 37 ladrões na noite seguinte: "They kept the secret to themselves, and the next night buried the thirty-seven thieves in a deep trench at the bottom of the garden" (FAVOURITE, 1869, 22). ${ }^{16}$

Finalmente, o chapbook intitulado Ali Baba, or the Forty Robbers (1886) contém 16 páginas. É muito provável que tenha sido diretamente adaptado a partir da edição de Scott, como evidencia sua descrição do enterro dos ladrões: "The next morning she told Ali Baba of what she had done, and he and one of his servants dug a trench in his garden in which they buried the robbers" (ALI, $1886,9) .{ }^{17}$ Esse chapbook é o único que oferece a mesma versão dada por Scott a esse enterro, afirmando explicitamente que Ali Babá, auxiliado por um de seus escravos - que na versão de Scott é o escravo Abdalla -, enterrou os 39 ladrões na manhã seguinte ao seu assassinato.

\section{Noites inconclusas}

Segundo Jorge Luis Borges (1984), bastaria enumerar os títulos incorporados por Galland à coletânea árabe para demonstrar que o tradutor francês criou um cânone literário constituído por fábulas que, tornadas indispensáveis com o tempo, não poderiam mais ser omitidas pelos tradutores vindouros. No entanto, nem todas as versões inglesas de As mil e uma noites incluem a fábula de Ali Babá - na verdade, as três primeiras traduções diretas da coletânea árabe para o inglês, realizadas por Henry Whitelock Torrens (1838), Edward William Lane (1838-1841) e John Payne (1882-1884), excluíram essa fábula, considerada na época como uma invenção de Galland e, portanto, como uma interpolação de uma fábula inautêntica no interior da coletânea árabe.

Todas essa traduções diretas de As mil e uma noites - em particular, as traduções de Lane e de Payne - foram muito criticadas por essa exclusão. Por esse motivo, tanto o tradutor Richard Burton (1886-1888) quanto o editor e revisor da tradução de Lane, o seu sobrinho Stanley Lane-Poole (1909), reintroduziram aquela fábula em suas respectivas edições. Isso prova que, desde meados do 
século XIX, quando foi publicada a primeira tradução direta para o inglês de As mil e uma noites por Lane, as traduções anteriores para essa língua já tinham criado um cânone para a coletânea árabe - e a fábula de Ali Babá e os quarenta ladrões constituía um de seus títulos mais representativos.

Publicados durante o século XIX, todos os chapbooks de Ali Babá analisados anteriormente se baseiam na edição revisada por Jonathan Scott da tradução indireta de Grub Street. Graças à sua intensa disseminação pelos chapbooks da fábula de Ali Babá, foi promovida sua popularização nos países anglófonos durante os séculos XVIII e XIX. Portanto, a tradução anônima de Grub Street inaugurou a tradição editorial responsável pela enorme popularidade alcançada pela fábula de Ali Babá. É bem verdade que essa popularidade não deixa de ser irônica, como afirma Arata (2008), caso se considere que essa fábula foi, muito provavelmente, introduzida na coletânea árabe pelo tradutor francês.

A partir da primeira metade do século XIX, as traduções indiretas para o inglês de As mil e uma noites começaram a se tornar menos aceitas, pois, como textos mediados, essa modalidade tradutória estaria excessivamente distante do original. No entanto, todas as traduções para o inglês de fábulas órfãs, como a de Ali Babá, foram realizadas a partir da versão francesa, independemente de terem sido incluídas em traduções diretas ou em traduções indiretas. As discussões filológicas iniciadas naquele período sobre as possíveis fontes daquela fábula continuam até hoje; nem por isso, ela perdeu sua importância no imaginário comum, a qual, pelo contrário, não cessou de crescer.

Mesmo que o manuscrito árabe da fábula de Ali Babá supostamente utilizado por Galland fosse descoberto, ela não poderia mais ser dissociada da coletânea maior a que pertence. Como foi visto, o chapbook condensado de 1816 introduziu variantes na fábula de Ali Babá, as quais foram transmitidas aos chapbooks subsequentes que se basearam nele. Portanto, a popularização dessa fábula pela fórmula editorial do chapbook não deixou de disseminar variantes, confirmando a tópica de que cada edição é uma nova versão. Aliás, essa tópica talvez nunca tenha se revelado tão verdadeira quanto no caso da fábula de Ali Babá - ela que não possui um único original, mas 1001 versões.

\section{Notes}

1. Ao longo deste artigo, o termo fábula deve ser entendido, em sentido amplo, como matriz ficcional, e não, em sentido restrito, como alegoria de animais.

2. Em sua obra mais influente, Orientalism: Western Representations of the Orient (1977), Edward Said distingue três dimensões interdependentes do orientalismo, definido como "um modo de lidar com o Oriente baseado no lugar especial ocupado pelo Oriente na experiência ocidental europeia" (Said, 1977, 1, tradução nossa). Como disciplina acadêmica, um estilo de pensamento e uma instituição do poder colonial europeu, o orientalismo teria permitido administrar - e até produzir - política, sociológica, ideológica, científica e imaginativamente não apenas o Oriente, mas, inversamente, o próprio Ocidente, entendido como uma auto-definição da própria identidade ocidental por contraste: “[...] o Oriente ajudou a definir a Europa (ou o Ocidente), por contraste com sua imagem, ideia, personalidade e experiência” (Said, 1977, 2, tradução nossa). 
3. Apenas para citar alguns exemplos: William Beckford, Samuel Taylor Coleridge, William Wordsworth, Alfred Tennyson, William Makepeace Thackeray, Charles Dickens, Elizabeth Gaskell, Edgar Allan Poe, Gustave Flaubert, Stendhal, Goethe, Alexandre Dumas, Marcel Proust, Leo Tolstoy, Jorge Luis Borges e Marina Warner.

4. O trabalho de Lane só deve ser considerado como a primeira tradução direta se for excetuada a anônima tradução parcial realizada no final do século XVIII, presente no manuscrito de William Beckford (Moussa-Mahmoud, 1976).

5. Divertimentos das noites árabes, consistindo em mil contos: narrados pela sultana das índias para impedir o sultão de executar o sangrento juramento empenhado de se casar com uma nova esposa todo dia e cortar sua cabeça no dia seguinte, a fim de se vingar da infidelidade de sua primeira sultana, contendo igualmente um relato melhor dos costumes, hábitos e religião das nações orientais, particularmente os tártaros, persas e indianos do que pode ser encontrado em qualquer autor publicado até agora (tradução nossa).

6. Segundo Márcia Abreu $(2002,86)$, foram enviados seis exemplares de Les mille et une nuits ao Rio de Janeiro até 1807 e sete exemplares de Les mille et un quartd'heure: contes Tartares, de Gueullette, que foi traduzido para o português por Paulo Silvério de Lima com o título Divertimentos de um quarto de hora (1782). A partir de 1815, essa edição começou a ser remetida diversas vezes ao ano. Durante o século XIX, foram enviados ao Brasil "cinquenta e cinco exemplares" da tradução de Galland (Abreu, 2002, 132).

7. Entre esses tradutores, encontram-se, por exemplo, Aquilino Ribeiro, Branquinho da Fonseca, João Gaspar Simões, Domingos Monteiro, Jorge de Sena, Irene Lisboa, David Mourão Ferreira, Carlos de Oliveira, José Saramago e José Rodrigues Miguéis.

8. Divertimentos das Noites Árabes: consistindo em mil e uma histórias cuidadosamente revisadas e ocasionalmente corrigidas a partir do árabe, à qual se acrescenta uma seleção de novos contos agora traduzidos pela primeira vez dos originais árabes, bem como uma introdução e notas ilustrativas à religião, hábitos e costumes dos maomedanos (tradução nossa).

9. Mahdi sugere que Jean Varsy tivesse sido um discípulo do célebre orientalista Silvestre de Sacy (1758-1838), mas Jarouche (LIVRO, 2012) e Zakharia (2017) lançam fortes dúvidas sobre essa hipótese.

10. Utilizado pela tradução de Richard Burton, o manuscrito árabe de Aladim e a lâmpada mágica foi transcrito por um padre sírio chamado Dionysius Shawish (aliás Dom Denis Chavis), que morava em Paris. Entre 1805 e 1808, a fábula foi novamente transcrita em um manuscrito pelo colaborador sírio do orientalista Silvestre de Sacy, chamado Mikhail Sabbagh. Burton encontrou esse manuscrito na Biblioteca Nacional da França, em Paris. Embora Sabbagh afirme tê-la copiado de um manuscrito de 1703 oriundo de Bagdad, a comparação entre as duas versões pelo crítico iraquiano Muhsin Mahdi (2008) revelou que a versão árabe é uma retrotradução da francesa. Da mesma forma que a fábula de Ali Babá, a versão mais antiga da fábula Aladim também corresponde à tradução de Galland (Mahdi, 2008), intitulada Histoire d'Aladdin, ou la lampe merveilleuse. Diferentemente do que ocorre com o manuscrito árabe da fábula de Ali Babá, o da fábula de Aladim e a lâmpada mágica é unanimemente considerado uma retrotradução da versão de Galland. Tendo sido realizada a partir do manuscrito falsificado, a tradução de Burton para o inglês dessa fábula, intitulada Aladdin; or the Wonderful Lamp (1888), deve ser considerada, portanto, como uma tradução indireta da versão francesa mediada pela tradução árabe.

11. Essa edição, por sua vez, foi traduzida para o inglês por Husain Haddawy (2008).

12. O termo em inglês chapbook está, como o termo em francês littérature de colportage, associado aos vendedores ambulantes, que vendiam livros a preços baixos para diferentes parcelas da população. O chapbook é composto por um papel de baixa qualidade cuja configuração material corresponde à da brochura. Inicialmente, ele é acompanhado por imagens impressas, como xilogravuras, e, mais tarde, 
metalogravuras, segundo a evolução da própria prensa. Os chapbooks foram impressos às centenas de milhares a partir da segunda metade do século XVII (Chartier, 1990).

13. 'O que devemos fazer, é enterrar imediatamente os corpos dessa peste do gênero humano guardando absoluto segredo, para que ninguém suspeite do que aconteceu com eles. Mas eu e Abdalla realizaremos esse trabalho'. No fundo do quintal de Ali Babá, que era muito extenso, havia um grande número de árvores frondosas. Sob essas árvores, ele cavou uma vala larga o suficiente para que os ladrões coubessem nela; e, como o terreno era fofo, eles não demoraram a fazê-lo (tradução nossa).

14. E sem deixar ninguém descobrir o segredo, ele e Morjana enterraram na noite seguinte os 37 ladrões em uma vala profunda no fundo do quintal (tradução nossa).

15. Sem deixar ninguém descobrir o segredo, Ali Babá e Morjana enterraram na noite seguinte os 39 ladrões no fundo do quintal (tradução nossa).

16. Eles guardaram o segredo para si mesmos e, na noite seguinte, enterraram os 37 ladrões em uma vala profunda no fundo do quintal (tradução nossa).

17. Na manhã seguinte, ela contou a Ali Babá sobre o que tinha feito, e ele e um de seus escravos cavaram em seu quintal uma vala, na qual enterraram os ladrões (tradução nossa).

\section{Referências}

ABREU, M. Histórias de Cordéis e Folhetos. Campinas, SP: Mercado de Letras, 1999.

ABREU, M. Leituras no Brasil Colonial. Revista Remate de Males, Campinas, SP, v. 22, 2002, p. 131-163.

ALI Baba; or the forty thieves destroyed by Morgiana, a slave. Stirling: J. Fraser \& Co. printers, 1816.

ALI Baba: or the story of the Forty Thieves, an interesting tale. Glasgow: Printed for the booksellers, 1850 .

ALI Baba, or the Forty Robbers. New York: McLoughlin, 1886.

ARABIAN Nights' Entertainments: consisting of One Thousand and One Stories. London: A. Bell, 1706. 4 v.

ARABIAN Nights' Entertainments: consisting of One Thousand and One Stories. London: Piguenit, 1792. 4 v.

ARATA, S. On E. W. Lane's Edition of The Arabian Nights' Entertainments, 1838. BRANCH: Britain, Representation and Nineteenth-Century History. London, 2014, p. 1007-1028.

AS MIL e uma noites. Tradução de Martim Velho Sotto Mayor. Lisboa: Estampa, $19-? .6 \mathrm{v}$.

AS Mil e uma noites. Versão de Antoine Galland. Tradução de Alberto Diniz. Apresentação de Malba Tahan. Rio de Janeiro: Ediouro, 1991. 2 v.

AS MIL e uma noites. Tradução de Nair Lacerda e Domingos Carvalho da Silva. Superv. Suleiman Khalil Safady. São Paulo: Saraiva, 1961. 8 v.

AS MIL e uma noites. Tradução de Monteiro Lobato. São Paulo: Cia. Nacional, 2007.

BORGES, Jorge Luis. Obras Completas (1923-1972). Buenos Aires: Emecé Editores, 1984.

CHARETI, A. F. Abu Nuwas e a inovação da poesia árabe. In: Anais do IX Ciclo de Estudos de Linguagem e II Congresso Internacional de Estudos de Linguagem, 
2017, Ponta Grossa. Anais eletrônicos... Campinas, GALOÁ, 2018. Disponível em: <https://proceedings.science/ciel-2017/papers/abu-nuwas-e-a-inovacao-dapoesia-arabe?lang=pt-br>. Acesso em: 10 jul. 2018.

CHARTIER, R. Textos e edições: a 'literatura de cordel. In: A história cultural. Lisboa: Difel, 1990.

CHRAÏBI, A. Galland's 'Ali Baba' and the Other Arabic Versions. In: Marzolph, U. (Org.). The Arabian Nights in Transnational Perspective. Detroit: Wayne State University Press, 2007, p. 3-15.

FAVOURITE Fairy Tales. Edimburg: Gall de Inglis, 1869.

GALLAND, A. Discours. In: Herbelot, Barthélemy. Bibliothèque orientale, ou Dictionnaire universel contenant tout ce qui fait connaitre les peuples de l'Orient. The Hague: Neaulme \& van Daalen, 1777.

GERHARDT, M. The Art of Story-telling: A Literary Study of the Thousand and One Nights. Leiden: Brill, 1963.

GUEDES, M. I. C. Galland, autor das Mil e uma noites. Gragoatá, Niterói, n. 13, p. 131-145, 2002.

HADDAWY, H. Introduction. In: The arabian nights: Sindbad and other popular stories. New York: W. W. Norton \& Company, 1995. v. 2.

HISTORY of the Forty Robbers. New York: J. Wrigley, 1867.

JAROUCHE, M. M. O Livro das Mil e uma Noites: dilemas e opcões de uma tradução. Revista Veredas, Porto Alegre, v. 8, p. 361-371, 2007.

KERVEN, R. Aladim e outros contos de As mil e uma noites. Tradução de Hildegard Kerven. São Paulo: Cia. das Letras, 1998.

LESLIE, S. (Ed.). Dictionary of National Biography. Sheares: Elder Smith, 1897. v. 51.

LES MILLE et une nuits. Traduit par Antoine Galland. Paris: Barbin, 1704-1717. 12 v.

LIVRO das mil e uma noites. Tradução de Mamede Jarouche. São Paulo: Globo (Biblioteca Azul), 2005. $1 \mathrm{v}$.

LIVRO das mil e uma noites. Tradução de Mamede Jarouche. São Paulo: Globo (Biblioteca Azul), 2012. $4 \mathrm{v}$.

MACDONALD, D. B. "Ali Baba and the Forty Thieves" in Arabic from a Bodleian MS. Journal of the Royal Asiatic Society of Great Britain and Ireland, Cambridge, n. 3, p. 327-386, apr./1910.

MACDONALD, D. B. "Further Notes on 'Ali Baba and the Forty Thieves"'. Journal of the Royal Asiatic Society of Great Britain and Ireland, Cambridge, p. 41-53, jan./1913.

MACK, R. L. Arabian Night's Entertainments. Oxford, USA: Oxford University Press, 2006.

MAHDI, M. Retranslation: An arabic version of 'Ali Baba'. In: Mahdi, Muhsin (Ed.). The Thousand and one nights: from the earliest known sources. Part 3: Introduction and indexes. Leiden: Brill, 1994, p. 72-86.

MAHDI, M. (Ed.) The Arabian nights. Translated by Husain Haddawy. New York: W. W. Norton \& Company, 2008.

MARZOLPH, U.; v. Leeuwen, R. The Arabian Nights Encyclopedia. Santa Barbara: ABC-CLIO2004. 2 v.

MOUSSA-MAHMOUD, F. A Manuscript Translation of the "Arabian Nights" in the Beckford Papers. Journal of Arabic Literature. Leiden, v. 7, n. 1, p. 7-23, 1976. 
SAID, E. Orientalism: Western Representations of the Orient. London: Penguin, 1977.

SCOTT, J. (Ed.). Arabian Nights' Entertainments: consisting of One Thousand and One Stories. London: Longman, 1811. $6 \mathrm{v}$.

SOUZA, R. de. O processo de criação da tradução das mil e uma noites de D. Pedro II: edição genética. 2015. 743 f. Tese (Doutorado em Estudos da Tradução) Programa de Pós-Graduação em Estudos da Tradução, Universidade Federal de Santa Catarina, Florianópolis, 2015.

STORIES from The Thousand and One Nights. Translated by Edward William Lane. Revised by Stanley Lane-Poole. New York: P. F. Collier \& Son, 1909.

SUPPLEMENTAL Nights to the book Thousand Nights and a night, with notes anthropological and explanatory. Translated by Richard Burton. London: Shammar, 1886-1888. $6 \mathrm{v}$.

THE BOOK of the Thousand Nights and a Night. Translated by John Payne. New York: R. Worthington, 1882-1884. $9 \mathrm{v}$.

THE BOOK of the Thousand Nights and a Night. Translated by Richard Francis Burton. London: Shammar, 1885. $10 \mathrm{v}$.

THE STORY of the forty robbers destroyed by a slave. New York: Charles Scribner's sons, 1895.

THE THOUSAND and one nights, Commonly Called, in England, The Arabian Nights' Entertainments. A New Translation from the Arabic, with Copious Notes. Translated by Edward William Lane. London: Charles Knight, 1838-41. 3 v.

TOURY, G. A lesson from indirect translation. In: (Ed.). Descriptive translation studies and beyond. Amsterdam/Philadelphia: John Benjamins, 1995, p. 129-146.

VASCONCELLOS, P. S. (Org.). As mil e uma noites: contos selecionados. São Paulo: Sol, 2008.

ZAKHARIA, K. La version arabe la plus ancienne de l' "Histoire d'Ali Baba": si Varsy n’avait pas traduit Galland? Réhabiliter le doute raisonnable. Arabica, Leiden, vol. 64, p. 50-77, 2017. 